\title{
Comparing the needs and utilization of health services between urban residents and rural-to-urban migrants in China from 2012 to 2016
}

\author{
Lingling Zheng ${ }^{1}$, Ruwei $\mathrm{Hu}^{2}$, Zichuan Dong ${ }^{3}$ and Yuantao $\mathrm{HaO}^{4^{*}}$
}

\begin{abstract}
Background: With a large population of internal migrants from all over the world, China has the largest number of internal floating migrants, and most of them (up to 169 million in 2016) are rural-to-urban migrants. Those migrants have difficulty accessing essential health care services because of Hukou, leading to disparities in health needs and utilization between rural-to-urban migrants and residents. To compare the needs and utilization of health services between urban residents and rural-to-urban migrants in China from 2012 to 2016.

Method: We used longitudinal data from the Chinese Labor Dynamic Survey (CLDS) with three waves in 2012, 2014 and 2016. Descriptive analysis was employed to show self-reported illnesses and health services utilization among locals and migrants in the most recent 2 weeks in China. Chi-square tests and log binomial regression models were constructed to explore factors influencing health care needs and utilization.

Result: A total of 19.97\% of respondents were rural-to-urban migrants, with an upward trend from 2012 to 2016. Rural-to-urban migrants (11.99\%) had higher needs for health services than urban residents (10.47\%) in general, while urban residents and migrants had no differences in needs in 2012. Besides, there was no difference in the utilization of health services between residents and migrants in 2012, 2014 or 2016. In addition, increased age, male sex, poor medical insurance coverage and dissatisfaction with income were found to have negative effects on health care needs.

Conclusion: This study has shown that the rural-to-urban migrants had higher health care needs but the same health care utilization compared with urban residents in China. Health policies focusing on equitable health outcomes should pay more attention to rural-to-urban migrants in China's health care system reform.
\end{abstract}

Keywords: Needs and utilization of health services, Rural-to-urban migrants, Urban residents, China

\section{Background}

An estimated 740 million internal migrants globally are on the move ${ }^{1}$. Protection of the human rights regarding the health of migrants has been increasingly recognized and has attracted international attention [1]. WHO has been promoting the health of migrants and committed to adequately address health needs for migrants as part

\footnotetext{
*Correspondence: haoyt@mail.sysu.edu.cn

${ }^{4}$ Department of Medical Statistics and Epidemiology, School of Public Health, Key Laboratory of Health Informatics, Sun Yat-sen Global Health Institute, Sun Yat-sen University, 74 Zhongshan Roadll, Guangzhou 510080, Guangdong Province, China

Full list of author information is available at the end of the article
}

of the global compact for orderly and regular migration. ${ }^{1}$ Migrants face many obstacles in accessing essential health care services due to factors such as irregular immigration status, language barriers, a lack of migrantinclusive health policies and inaccessible public services. A framework for migrants' health by the WHO has recognized an urgent need for the health sector to address the impact of migration health more effectively.

China was reported as a country with the largest internal floating population (up to 253 million in 2012) around the world [2]. The primary part of this internal floating population are the rural-to-urban migrants, who

(c) The Author(s). 2018 Open Access This article is distributed under the terms of the Creative Commons Attribution 4.0 International License (http://creativecommons.org/licenses/by/4.0/), which permits unrestricted use, distribution, and 
always have been called "Peasant workers". ${ }^{2}$ There were 169 million rural-to-urban migrants in China in 2016 [3]. Internal rural-to-urban migration was modeled as a response to the disparities between the urban and rural sectors [4]. Due to their comparatively poorer social and economic status, these migrants usually lived in poorer environments [1] and had limited access to a range of public services [5]. Moreover, the rapid growth of available wealth and labor welfare has not been distributed evenly among the workforce population, leading to increased disparities in health services utilization among the different sectors of the population [6].

Rural-to-urban migrants do not qualify for public health services and other assistance services [7] such as employment, education, housing and social services [8]. Some researchers have confirmed that rural-to-urban migrants have a higher risk of three main diseases in China: infectious diseases, maternal health and occupational diseases, and injuries [7]. According to the framework for migrants, they have the fundamental right of equality, as all human beings, to the enjoyment of an attainable standard of health, without the distinction of social or economic conditions.

The WHO acknowledges that laws, regulations and policies governing access to health services by migrants vary across countries and are determined by national laws, policies and priorities. ${ }^{3}$ China's unique Hukou (the nationwide household registration system) originally was designed to regulate rural outflows and serve as a basis for resource allocation to specific groups. As rapid urbanization has occurred over the past 30 years, Hukou no longer limits to urban migration but still affects migrants' lives in urban areas, such as children's education, social welfare or access to health care [9], which hinders the implementation of universal health coverage in China. Similarly, the internal passport system may obstruct equity appearing in other countries, including Australia, Japan and some European countries [10]. Experiences from other countries suggest that a multisector approach is required to overcome these obstacles, which must be tailored to address the specific needs of migrants.

Previous studies have focused on immigrants' health demands in different countries or regions, such as the United States [11], England [12, 13], Australia [14], and Canada [15], as well as different subgroups of a population, such as pregnant women [16], adolescents with mental disorders [17, 18], and HIV-infected adults [19]. In China, more attention is paid to the equity issues of the utilization of health services [20-23]. Most of the previous studies mainly explored the situation or influencing factors of need and utilization of health services among rural-to-urban migrants and showed inequalities in health demands and health services utilization among migrants $[24,25]$ There is a shortage of research on the discussion of the disparities in health needs and utilization between rural-to-urban migrants and urban residents in China. Therefore, this paper mainly discusses the disparities and utility of health services between rural-to-urban migrants and urban residents by using a nationwide investigative public database and explores some relevant factors governing migrants' health needs and health services utilization.

\section{Methods}

\section{Data and sampling}

The data ${ }^{4}$ were derived from the Chinese Labor Dynamic Survey (CLDS), which was a nationally representative panel survey of China. CLDS covered 29 provinces, excluding Hong Kong, Macau, Taiwan, Tibet and Hainan, with a multistage cluster, and stratified, probability proportionate to size sampling (PPS) sampling strategy conducted by Sun Yat-sen University. Three waves of follow-up surveys in 2012, 2014 and 2016 have been completed. A total of 22,720 respondents were recruited from urban areas in these three surveys.

\section{Subjects}

The definition by the Chinese government of the floating population [26] refers to population separating from their household register, excluding living in other district/town in the city. In this study, we mainly explored urban residents (who have a nonagricultural household in the urban areas and live in the same urban areas) and rural-to-urban migrants (who have an agricultural household and live in the urban areas).

In 2012, the respondent was identified as belonging to the floating population if they answered 'no' to I1.15: "Is your household registration in this city/county?" and 'yes' to I1.15.1: "Has it been more than half a year since you were away from your place of household registration?" In 2014 and 2016, the respondent was classified as part of the 'floating population' if they chose the answer "in other subdistrict/town of the same county" or "in other county" to I1.3.2: "where is your household registration?" and 'yes' to I1.16 (same with I1.15.1 in 2012).

According to the items mentioned above, we could distinguish between the floating population and nonfloating population. Then, according to the type of household, we could further classify them into urban residents and rural-to-urban migrants, with a total of 14,590 respondents in the three surveys. The Fig. 1 showed the flow chart of this study subjects. Moreover, according to the judgment of reliability of the survey by the investigators, the respondents who were considered unreliable and very unreliable were excluded. Finally, 14,119 (96.77\%) respondents were included in our analysis. 


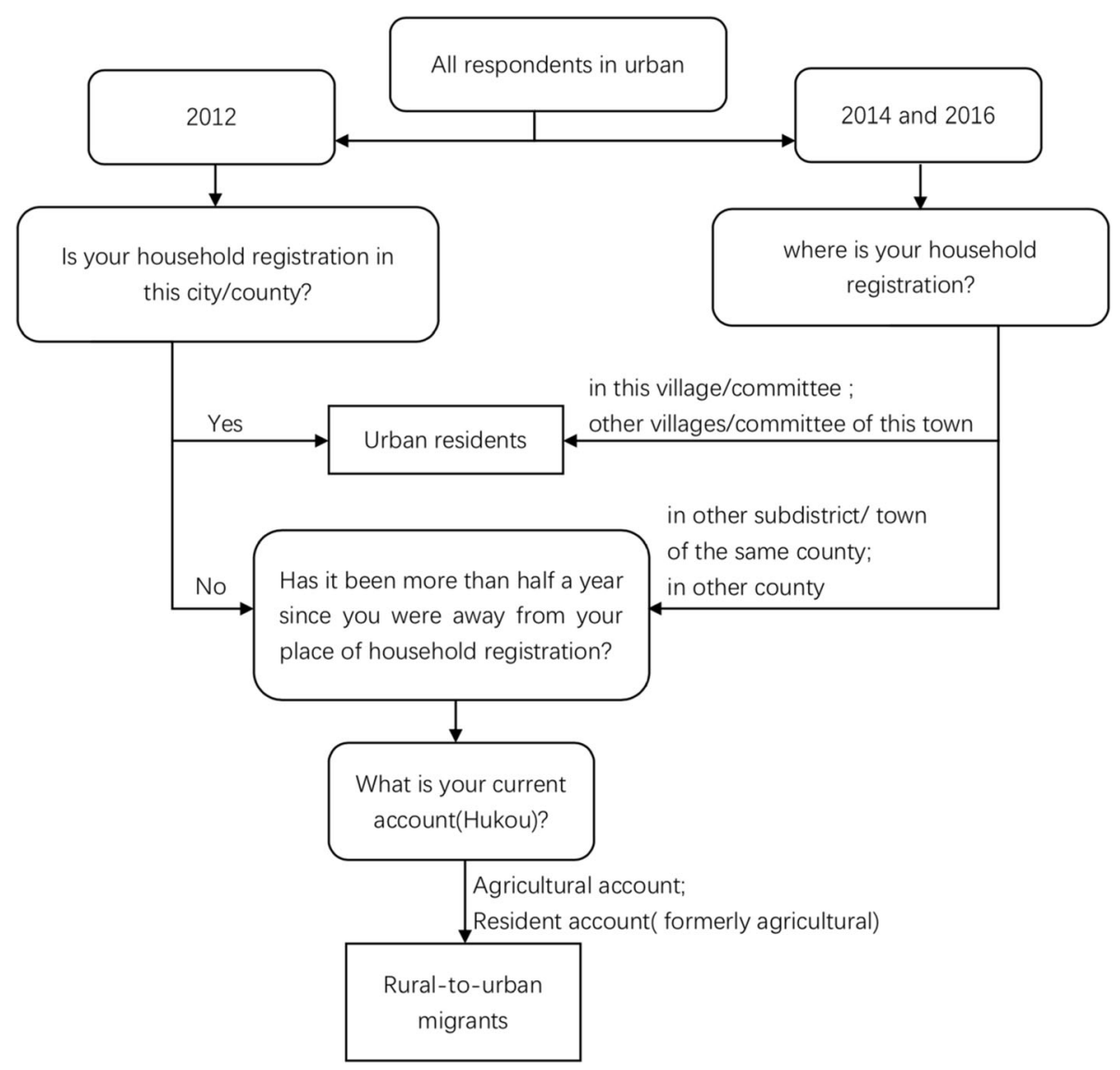

Fig. 1 The flow chart of the study subjects

\section{Variables and measurement}

\section{The needs and utilization of health services}

The needs of health services were represented by the person being sick in the past two weeks' (I19.7: "Have you ever been ill over the past two weeks?")

The utilization of health services was represented by 'the person visiting the clinic in the past two weeks' (I19.7.1: "Did you see the doctor over the past two weeks?")

\section{Demographic factors}

Demographic characteristics in this paper include age (age $15-24=0$, age $25-34=1$, age $35-44=2$, age $45-59=3$, age $\geq 60=4$ ), gender (female $=0$, male $=1$ ), marital status ( unmarried $=0$, married or living together $=1$, divorce or widowed $=2$ ).

\section{Socioeconomic factors}

Socioeconomic variables include education level (primary or less $=0$, junior high school or senior high school $=1$, college or above $=2$ ), having medical insurance (yes $=1$, no $=0$ ), being employed (yes $=1$, no $=0$ ), work time per week and individual income in the past year (analyzed as a continuous variable), self-perception on current job's income (a 5-point Likert response scale of "very satisfactory", "satisfactory", "fairy", "unsatisfactory", "very unsatisfactory"), and self-assessment of own social status (point 1-10; the highest social strata $=10$, the lowest social strata $=1$ ).

\section{Health status}

Health status used self-reported health (categorized into 3 groups: "Healthy", "Fair" and "Unhealthy".

\section{Statistical analysis}

We used the "mean replacement method" or "Maximum likelihood replacement method" to address the missing continuous or discrete variables data [27-29]. The chi-square test was used to analyze the differences between urban residents and rural-to-urban migrants regarding demographic, socioeconomic, health status and health-related behavior factors. A logistic regression was applied with weighted data to assess influences on the needs and utilization of health services. The forwardstepwise method was performed for variable selection. The statistical significance level was defined as 0.05. All 
statistical cleaning and analysis were performed using Stata version 13.1.

\section{Results \\ Descriptive analysis}

The frequency of urban residents and rural-to-urban migrants was reported by years in Table 1. In general, $19.97 \%$ of respondents were rural-to-urban migrants. The proportion of the rural-to-urban migrants shows an upward trend from 2012 to 2016.

The distribution of demographic, socioeconomic, health status and health-related behavior factors of study respondents were shown in Table 2. Urban residents and rural-to-urban migrants have no difference in gender distribution. Rural-to-urban migrants $(36.71 \pm 12.18$, age 15-34 accounting for $26.67 \%$ ) had a larger young and single population than urban residents $(43.7 \pm 13.75$, age 15-34 accounting for $48.35 \%$ ) and the proportion of rural-to-urban migrants (19.65\%) who had not been married was higher than that of urban residents (16.89\%). Urban residents had higher levels of education than rural-to-urban migrants, and the proportion of urban residents' education (9.73\%) through primary school or lower is lower than that of rural-to-urban migrants (23.98\%); education through high school (31.99\%) or above is much higher than that of migrants (12.31\%). More rural-to-urban migrants $(20.11 \%)$ did not have medical insurance than urban residents (15.26\%). Rural-tourban migrants had a higher proportion of being employed than did urban residents. Although migrants had a higher income, they were less satisfied with their income than were residents. Simultaneously, migrants reported a lower self-assessment of their own social status (4.00 \pm 1.78$)$. Migrants had a higher proportion of better self-reported health $(66.30 \%)$ and a lower proportion of self-reported illness (5.82\%) than did urban residents (62.46\% and $7.61 \%$, respectively). They had no differences in smoking and drinking. The largest proportion of migrants was found to be in the eastern region (59.95), while the smallest was in the western region $(15.01 \%)$ of China.

\section{Needs and utilization of health services}

The differences in needs and utilization of health services between urban residents and rural-to-urban migrants are

Table 1 The frequency of urban residents and rural-to-urban migrants by years

\begin{tabular}{llllllll}
\hline & \multicolumn{2}{l}{ Urban residents } & & \multicolumn{2}{l}{ Rural-to-urban migrants } & Total (n) \\
\cline { 2 - 3 } & $\mathrm{n}$ & $\%$ & & $\mathrm{n}$ & $\%$ & \\
\hline 2012 & 3650 & 83.72 & & 710 & 16.28 & 4453 \\
2014 & 4206 & 79.73 & & 1040 & 20.27 & 5523 \\
2016 & 3444 & 76.81 & & 2819 & 23.19 & 4604 \\
total & 11,300 & 80.03 & & 2819 & 19.97 & 14,119 \\
\hline
\end{tabular}

reported in Table 3. Rural-to-urban migrants (11.99\%) had higher health services needs than did urban residents $(10.47 \%)$ in general, while in 2012, urban residents and migrants had no differences. However, there was no difference in the utilization of health services between residents and migrants.

Three logistic models of health services needs are reported in Table 4. In model 1, we included all subjects in the model. Using the urban migrants as a reference group, this revealed in the model of rural-to-urban migrants $(\mathrm{OR}=1.19, P<0.05)$ that health services needs were significantly higher than those of the residents when controlling for other variables. We also separated residents and migrants to build two regression models. For the control variables, age had a negative relation to health services needs in model $1(\mathrm{OR}=0.99, P<0.001)$ and model $2(\mathrm{OR}=0.98, P<0.001)$. Males had a higher health services needs in all three models $(\mathrm{OR}=0.77, P<$ $0.001 ; \mathrm{OR}=0.78, P<0.001 ; \mathrm{OR}=0.74, P<0.05)$. Those who had medical insurance had higher needs in model 1 $(\mathrm{OR}=1.34, P<0.001)$ and $2(\mathrm{OR}=1.43, P<0.001)$, but there were no significant influences in model 3 . In model 1, those who were dissatisfied with their own income had higher needs than those who were satisfied with their income.

\section{Discussion}

The number of rural-to-urban migrants was large and showed an upward trend in the past few years. This result resembled the analysis of the Migrants Population Dynamic Monitoring Survey Data by National Bureau of Statistics. ${ }^{5}$ It seems that rural-to-urban migrants are still a growing group and shall continue to attract the government's concerns.

In the study, we determined that rural-to-urban migrants had higher needs. The recent two-week prevalence rate of illness among rural-to-urban migrants was $11.99 \%$. Compared to other studies in China, the outcomes were similar to that of general migrants in Beijing [30], Shanghai and Pearl River Delta Areas of Guangdong [31], with a rate ranging from 11 to $13.1 \%$, but lower than Shenzhen (24.51\%) [32] and Xi'an (18.22\%) [33]. Most studies directly compared their results with the data of the NHS (National Health Service) Survey, drawing the conclusion that the need of health services for migrants was lower than that of the general population. In contrast, we found rural-to-urban migrants (11.99\%) had higher health needs than urban residents $(10.47 \%, P<0.05)$, and was supported by model 1's results $(\mathrm{OR}=1.19$, CI: 1.03-1.37). Besides, more serious illnesses of the migrants might be associated with their poorer living conditions and socioeconomic status (SES) [34]. Thus, we focus on discovering the associated factors of health services need between rural-to-urban migrants 
Table 2 Distribution difference of characteristics between urban residents and rural-to-urban migrants

\begin{tabular}{|c|c|c|c|c|c|c|}
\hline & Urban residents $(n=11,300)$ & & Rural-to-urban migrants ( $n=$ & & & \\
\hline & $\mathrm{N}$ or $\mathrm{M} \pm \mathrm{SD}$ or $\mathrm{P}_{50}\left[\mathrm{P}_{25}, \mathrm{P}_{75}\right]$ & $\%$ & $\mathrm{~N}$ or $\mathrm{M} \pm \mathrm{SD}$ or $\mathrm{P}_{50}\left[\mathrm{P}_{25}, \mathrm{P}_{75}\right]$ & $\%$ & $F / X^{2}$ & $P$ \\
\hline Gender & & & & & 0.0048 & 0.95 \\
\hline Female & 6180 & 50.26 & 1569 & 51.54 & & \\
\hline Male & 5452 & 49.74 & 1379 & 48.46 & & \\
\hline Age & $43.7 \pm 13.75$ & & $36.71 \pm 12.18$ & & & $<0.001^{* *}$ \\
\hline $15 \sim 24$ & 1278 & 11.31 & 463 & 16.42 & & \\
\hline $25 \sim 34$ & 1736 & 15.36 & 900 & 31.93 & & \\
\hline $35 \sim 44$ & 2461 & 21.78 & 688 & 24.41 & & \\
\hline $45 \sim 59$ & 4281 & 37.88 & 641 & 22.74 & & \\
\hline $60 \sim$ & 1544 & 13.66 & 127 & 4.51 & & \\
\hline Marital status & & & & & 68.96 & $<0.001^{* *}$ \\
\hline Unmarried & 1909 & 16.89 & 554 & 19.65 & & \\
\hline Married, living together & 8808 & 77.95 & 2216 & 78.61 & & \\
\hline divorce, widowed & 583 & 5.16 & 49 & 1.74 & & \\
\hline Education Level & & & & & 687.30 & $<0.001^{* *}$ \\
\hline Primary or less & 1099 & 9.73 & 676 & 23.98 & & \\
\hline Junior middle school & 6586 & 58.28 & 1796 & 63.71 & & \\
\hline High school or above & 3615 & 31.99 & 347 & 12.31 & & \\
\hline Medical insurance & & & & & 39.15 & $<0.001^{* *}$ \\
\hline Yes & 9576 & 84.74 & 2252 & 79.89 & & \\
\hline No & 1724 & 15.26 & 567 & 20.11 & & \\
\hline Job & & & & & 442.62 & $<0.001^{* *}$ \\
\hline Yes & 5914 & 52.34 & 2094 & 74.28 & & \\
\hline No & 5386 & 47.66 & 725 & 25.72 & & \\
\hline Income in the past year & $20,000[4,45,000]$ & & $24,000[6,42,000]$ & & 2.376 & $0.018^{*}$ \\
\hline Satisfied with income & & & & & 40.67 & $<0.001^{* *}$ \\
\hline Satisfactory & 2984 & 26.41 & 610 & 21.64 & & \\
\hline Fair & 3699 & 32.73 & 1078 & 38.24 & & \\
\hline Unsatisfactory & 4617 & 40.86 & 1131 & 40.12 & & \\
\hline Self-assessment of social status & $4.57 \pm 1.80$ & & $4.00 \pm 1.78$ & & 227.33 & $<0.001^{* *}$ \\
\hline Self-reported health & & & & & 18.46 & $<0.001^{* *}$ \\
\hline Health & 7058 & 62.46 & 1869 & 66.30 & & \\
\hline Fair & 3382 & 29.93 & 786 & 27.88 & & \\
\hline Unwell & 860 & 7.61 & 164 & 5.82 & & \\
\hline Survey area & & & & & 279.68 & $<0.001^{* *}$ \\
\hline East & 4796 & 42.44 & 1690 & 59.95 & & \\
\hline Central & 3940 & 34.87 & 706 & 25.04 & & \\
\hline west & 2561 & 22.69 & 423 & 15.01 & & \\
\hline
\end{tabular}

** significance $P<0.001 ;{ }^{*} P<0.05$

and urban residents, searching for a new angle to promote health equality.

First, age and gender showed to have influence on health service needs, which was confirmed in other studies [35]. In models 1 and 2, age was a negative factor of health service needs, but no significant differences in model 3. The rural-to-urban migrants were younger than urban residents, and most of the migrants were under 44 years old, thus weakening the effect of age on health needs. Both female migrants (male's $\mathrm{OR}=0.74$, CI: 0.58-0.95) and female residents (male's $\mathrm{OR}=0.78$, CI: 0.69-0.89) had higher health needs. One possible 
Table 3 The difference of needs and utilization of health services between urban residents and rural-to-urban migrants

\begin{tabular}{|c|c|c|c|c|c|c|c|c|}
\hline & Urban & & & Rural- & migran & & $x^{2}$ & $P$ \\
\hline & Yes & No & Rate (\%) & Yes & no & Rate (\%) & & \\
\hline Needs & 1183 & 10,117 & 10.47 & 338 & 2481 & 11.99 & 5.43 & $0.020^{*}$ \\
\hline 2012 & 658 & 2992 & 18.03 & 125 & 585 & 17.61 & 0.072 & 0.79 \\
\hline 2014 & 249 & 3957 & 5.92 & 108 & 961 & 10.10 & 23.63 & $<0.001^{* *}$ \\
\hline 2016 & 276 & 3168 & 8.01 & 105 & 935 & 10.10 & 4.45 & $0.035^{*}$ \\
\hline Utilization & 710 & 473 & 60.02 & 208 & 130 & 61.54 & 0.25 & 0.61 \\
\hline 2012 & 423 & 235 & 64.29 & 84 & 41 & 67.20 & 0.39 & 0.53 \\
\hline 2014 & 152 & 97 & 61.04 & 61 & 47 & 56.48 & 0.65 & 0.42 \\
\hline 2016 & 135 & 141 & 48.91 & 63 & 42 & 60.00 & 3.75 & 0.053 \\
\hline
\end{tabular}

** significance $P<0.001 ;{ }^{*} P<0.05$

reason could be that females presumably were more aware of health problems and symptoms than males [36]. Or it could be that most female migrants moved into the urban setting because of marriage, and it was hard to get used to urban life, thus, they experience more mental or physical health issues.

Second, we determined that urban residents who were dissatisfied with their income had higher health needs $(\mathrm{OR}=1.30$, CI: $1.09,1.57)$, while rural-to-urban migrants did not show a significant difference. Besides, there was no significant difference between personal income and health needs. It turned out that regardless of income level, those who were dissatisfied with their income might have to push themselves to work harder or just complain a lot, either of these would end up in mental health problem if they didn't learn to deal with stress. Almost all rural-to-urban migrants currently focus on their economic conditions only, ignoring their own health, including physical health and mental health. In addition, with the progress of urbanization and the reform of the household registration system [37], an increasing number of rural-to-urban migrants would become urban residents. Mental health issues may begin to surface. Therefore, we suggest that the government pay attention to mental

Table 4 OR of health services needs between urban residents and rural-to-urban migrants

\begin{tabular}{|c|c|c|c|}
\hline \multirow[t]{2}{*}{ Variable } & $\begin{array}{l}\text { Model } 1 \\
\text { Total }\end{array}$ & \multirow{2}{*}{$\begin{array}{l}\text { Model } 2 \\
\text { Urban residents } \\
\text { OR(95\%Cl) }\end{array}$} & \multirow{2}{*}{$\begin{array}{l}\text { Model } 3 \\
\text { Rural-to-urban migrants } \\
\text { OR(95\%Cl) }\end{array}$} \\
\hline & $\mathrm{OR}(95 \% \mathrm{Cl})$ & & \\
\hline \multicolumn{4}{|l|}{ Urban resident (Ref) } \\
\hline Rural-to-urban migrant & $1.19^{*}(1.03,1.37)$ & - & - \\
\hline Age & $0.99^{* *}(0.98,0.99)$ & $0.98^{* *}(0.98,0.99)$ & $0.99(0.98,1.00)$ \\
\hline \multicolumn{4}{|l|}{ Female (Ref) } \\
\hline Male & $0.77^{* *}(0.69,0.86)$ & $0.78^{* *}(0.69,0.89)$ & $0.74^{*}(0.58,0.95)$ \\
\hline Medical insurance $($ Ref = no) & $1.34^{* *}(1.13,1.59)$ & $1.43^{* *}(1.17,1.76)$ & $1.13(0.83,1.53)$ \\
\hline \multicolumn{4}{|l|}{ Satisfied with income (Ref) } \\
\hline Fair satisfied with income & $1.12(0.95,1.32)$ & $1.14(0.94,1.36)$ & $1.09(0.76,1.56)$ \\
\hline Unsatisfied with income & $1.32^{* *}(1.12,1.54)$ & $1.30^{* *}(1.09,1.57)$ & $1.33(0.94,1.89)$ \\
\hline \multicolumn{4}{|l|}{ Self-report of health (Ref = Health) } \\
\hline Fair & $3.00(2.63,3.42)$ & $3.10^{* *}(2.66,3.60)$ & $2.56^{* *}(1.96,3.35)$ \\
\hline Unwell & $9.60(8.05,11.46)$ & $9.51^{* *}(7.81,11.59)$ & $9.32^{* *}(6.41,13.77)$ \\
\hline \multicolumn{4}{|l|}{ Area (Eastern Ref) } \\
\hline Central & $0.82^{* *}(0.72,0.94)$ & $0.82^{* *}(0.71,0.95)$ & $0.86(0.65,1.16)$ \\
\hline Western & $0.96(0.83,1.12)$ & $0.98(0.83,1.16)$ & $0.85(0.59,1.22)$ \\
\hline \multicolumn{4}{|l|}{2012 (Ref) } \\
\hline 2014 & $0.34^{* *}(0.30,0.39)$ & $0.31^{* *}(0.26,0.36)$ & $0.51^{* *}(0.38,0.68)$ \\
\hline 2016 & $0.43^{* *}(0.37,0.49)$ & $0.41^{* *}(0.35,0.48)$ & $0.53^{* *}(0.39,0.71)$ \\
\hline
\end{tabular}

** significance $P<0.001 ;{ }^{*} P<0.05$ 
health and prevent urban residents from suffering mental health.

Third, the health system is the main factor influencing health needs, and medical insurance plays an important part of the health system. We found urban residents with medical insurance had higher health needs, which is in accordance with previous studies [38]. We have two possible reasons. One is that high-quality health insurance requires a high price; it is also possible that those with medical insurance are more willing to invest in their health and have regular health examinations. However, we did not find the same results in the migrant model. Fewer rural-to-urban migrants who had medical insurance $(79.89 \%)$ than urban residents $(84.74 \%)$. Although the majority of rural-to-urban migrants are pursuing a better life in the urban areas, they are still fighting for more income and thus neglect their own health. According to the National Development and Reform Commission, at the end of 2011, there were more than 1.3 billion people participating in the basic medical insurance plan for urban and rural residents in China, with a coverage rate of more than $95 \%{ }^{6}$ Both proportions medical insurance for urban residents and rural-to-urban migrants were below this benchmark, which showed a phenomenon that some people already had basic medical insurance, but did not realize their insured status. This revealed that the basic medical insurance system was not being used effectively, even when the government strongly promoted it. We suggest that the government should strengthen health education and promote health insurance, while promoting national health insurance coverage.

Finally, we found that there were no significant difference in health care utilization between rural-to-urban migrants and urban residents. Contradicting previous studies, we do not agree that rural-to-urban migrants had lower health awareness or more barriers in accessing health services [39].In China, the Floating Population Service Center was established in December 2011 with the approval of the Central Committee and officially was launched in April 2014. ${ }^{7}$ One of the main tasks is to provide information for the management of migrant population health and health care services. This means that the Chinese government is aware of the situation of the floating population and has begun to enhance health and fairness.

Among those who had reported illnesses in the past 2 weeks, $61.54 \%$ of rural-to-urban migrants and $60.02 \%$ of urban residents had clinical visits within the past 2 weeks $(P=0.61)$, which is much higher than that reported in previous studies in China [30-32]. The improvement of health care utilization may be attributed to the promotion and implementation of health care reform in 2009-2011 [40]. One key issue of this reform is tiered medical services. By signing a contract between family physicians and residents [41], these services have demonstrated efficiency in improving health and promoting health service equity [42]. Although members of the floating population who had migrated more than 6 months prior were incorporated into the Family Physician Sign System, some problems still need to be addressed, such as how to deal with the continuity of signing for those who might migrate to many cites and how to strengthen migrants' health awareness.

\section{Limitations}

The study suffers from several limitations. It could be significant difference of years between urban residents and migrants and that needed more evidence and researches to prove. As Table 3 showed, we recognized a large drop in need for health services from 2012 to 2014 in both urban residents and migrants (from 18.03 to 5.92 in urban residents and from 17.61 to 10.10 in migrants). In 2012, the questions about health service needs were conducted vaguely. And in 2013, the National Health and Family Planning Commission of PRC operated a pilot work on equalization of basic public services for floating population $^{6}$. Therefore, using questionnaire in the pilot work as a reference, our questionnaire was reconstructed. Giving more definitions and standards, it could make sure both interviewer and interviewee understand well. Besides, recall bias may exist in a self-reported study, but this should be minimal due to the limited recall period of 2 weeks; collecting variables is based on a self-reported method and may be measured with errors; our study is cross sectional and thus does not allow such causality to be determined. And, health service utilization was also determined by the accessibility of health services in terms of geography, cultural and administrative barriers in addition to socioeconomic factors and quality issues. It is necessary to consider more associated factors in the future.

\section{Conclusion}

In conclusion, this study has shown that rural-to-urban migrants had higher health care needs and age and female had negative effect, but the same health care utilization compared with urban residents in China. Also, urban residents with medical insurance have higher health needs. Health policies focusing on health equity should pay more attention to the rural-to-urban migrants in shaping China's health care system reform.

\footnotetext{
Endnotes

${ }^{1}$ www.who.int/migrants/publications/WHO_IOM_UN OHCHR-Publication.pdf?ua $=1$

${ }^{2}$ www.stats.gov.cn/tjsj/zxfb/201804/t20180427_159638 9.html
} 


\author{
${ }^{3}$ FRAMEWORK OF PRIORITIES AND GUIDING \\ PRINCIPLES TO PROMOTE THE HEALTH OF REFU- \\ GEES AND MIGRANTS \\ ${ }^{4}$ The data can be applied and obtained from the CLDS \\ of Center for Social Survey, Sun Yat-sen University at \\ http://isg.sysu.edu.cn/node/353. More detail messages \\ about this survey also can be learned on the official \\ website mentioned above or the two previously pub- \\ lished papers [35, 43]. \\ ${ }^{5}$ http://www.chinaldrk.org.cn $/{ }^{6}$ http://www.nhfpc.gov.c \\ n/ldrks/s3578/201312/74b817920c644bb6a7b78a9d18fd3 \\ 449.shtml \\ ${ }^{6} \mathrm{http} / / /$ www.yaic.com.cn/news/show?cid=34\&id=1216 \\ ${ }^{7}$ http://www.chinaldrk.org.cn/wjw/news-update/\#notice
}

\section{Abbreviations}

CLDS: Chinese Labor Dynamic Survey; PPS: probability proportionate to size sampling; SES: socioeconomic status

\section{Acknowledgments}

We would like to thank all study participants for their time in being interviewed. We also thank the support of the CLDS teams for their open datasets and we especially give our gratitude to the advisement of Prof. Hao Lingxin and Prof. Cai He.

\section{Funding}

This study is funded by the China Medical Board (Grant number: 16-253 Health and Healthcare of Rural to Urban Migrants in China: Research and Research Capacity Building). The overall objective of the project is to continue to improve research on migrant health policy in China and to better understand Chinese migrants regarding their health problems and access to healthcare. One of the specific aims of the project is to provide an assessment of health and healthcare disparities between migrants and urban residents. At the preliminary stage, the project would explore the several nation level surveys in China, like CLDS, CFPS and CHNS to find some evidence about health and healthcare disparities between migrants and urban residents. This paper is one of the part of early research results.

\section{Availability of data and materials}

The data and all background materials are available upon request. The data can be applied and obtained from the CLDS of Center for Social Survey, Sun Yat-sen University at http://isg.sysu.edu.cn/node/353.

\section{Authors' contributions}

LLZ contributed to the design and preparation of the manuscript and finalized the article. RWH, ZCD contributed to join in designing and interpretation of data, and revised the draft of the manuscript together. YTH conceived the study, coordinated the research team. All authors contributed to interpreting the data and the various drafts of the paper. All authors reviewed and approved the final version.

\section{Ethics approval and consent to participate}

The study was conducted in accordance with the Declaration of Helsinki, and the protocol was approved by the Institutional Review Board of Sun Yat-sen University. Written informed consent has been obtained from all respondents.

\section{Consent for publication}

All presentations of case reports have consent to publish and have signed a form.

\section{Competing interests}

The authors declare that they have no competing interests.

\section{Publisher's Note}

Springer Nature remains neutral with regard to jurisdictional claims in published maps and institutional affiliations.

\section{Author details}

'Department of Medical Statistics and Epidemiology, School of Public Health, Sun Yat-sen University, Guangzhou 510080, Guangdong Province, China. ${ }^{2}$ Department of health management, School of Public Health, Sun Yat-sen University, Guangzhou 510080, Guangdong Province, China. ${ }^{3}$ State Key Laboratory of Infectious Disease Prevention and Control National Institute for Communicable Disease Control and Prevention, Chinese Center for Disease Control and Prevention, No.155, Changbai Road, Changping District, Beijing 102206, China. ${ }^{4}$ Department of Medical Statistics and Epidemiology, School of Public Health, Key Laboratory of Health Informatics, Sun Yat-sen Global Health Institute, Sun Yat-sen University, 74 Zhongshan Roadll, Guangzhou 510080, Guangdong Province, China.

Received: 19 July 2018 Accepted: 4 September 2018

Published online: 17 September 2018

\section{References}

1. Health M. Healthy migrants in healthy communities. International Organization for Migrants. 2011.

2. Reporter Gan BB. Providing more equal health protection for floating population. In: Health News; 2017. p. 1.

3. National Bureau of Statistics of China. Migrants population dynamic monitoring survey data in 2016. In: China Information News; 2017. p. 9.

4. Adams RH. Remittances, investment, and rural asset accumulation in Pakistan. Econ Dev Cult Chang. 1998;47(1):155-73.

5. Zhang J, Lin S, Liang D, Qian Y, Zhang D, Hou Z. Public health services utilization and its determinants among internal migrants in China: evidence from a nationally representative survey. Int I Environ Res Public Health. 2017;14(9):1002.

6. Xie X, Wu Q, Hao Y, Yin H, Fu W, Ning N, Xu L, Liu C, Li Y, Kang Z. Identifying determinants of socioeconomic inequality in health service utilization among patients with chronic non-communicable diseases in China. PLoS One. 2013;9(6):e100231.

7. Hu X, Cook SSalazar MA. Internal migration and health in China. Lancet. 2008:372(9651):1717

8. Strand D. Contesting citizenship in urban China: peasant migrants, the state, and the logic of the market by Dorothy J. Solinger. China Q. 2000;161(1): $247-8$.

9. Jan C, Zhou X, Stafford RS. Improving the health and well-being of children of migrant workers. B World Health Organ. 2017;95(12):850-2.

10. European report on preventing child maltreatment. 2013.

11. Aarons GA, Glisson C, Green PD, Hoagwood K, Kelleher K, Landsverk JA, Weisz JR, Chorpita B, Gibbons R. The organizational social context of mental health services and clinician attitudes toward evidence-based practice: a United States national study. Implement Sci. 2012;7(1):1-15.

12. Guest JF, Ayoub N, Mcilwraith T, Uchegbu I, Gerrish A, Weidlich D, Vowden $\mathrm{K}$, Vowden P. Health economic burden that different wound types impose on the UK's National Health Service. Int Wound J. 2017;14(2):322-30.

13. Miqdad A, Shehzad A, Tim D, Brian F, Robert F, Maria G, Peter G, Mauro L, Rosalind R, Richard C. How a universal health system reduces inequalities: lessons from England. J Epidemiol Community Health. 2016;70(7):637-43.

14. Amuron B, Namara G, Birungi J, Nabiryo C, Levin J, Grosskurth H, Coutinho A, Jaffar S. Mortality and loss-to-follow-up during the pre-treatment period in an antiretroviral therapy programme under normal health service conditions in Uganda. BMC Public Health. 2009;9(1):1-6.

15. Mcdonald JT, Kennedy S. Insights into the 'healthy immigrant effect': health status and health service use of immigrants to Canada. Soc Sci Med. 2004;59(8):1613-27.

16. Ahmed S, Creanga AA, Gillespie DG, Tsui AO. Economic status, education and empowerment: implications for maternal health service utilization in developing countries. PLoS One. 2010;5(6):e11190.

17. Wang PS, Aguilargaxiola S, Alonso J, Angermeyer MC, Borges G, Bromet EJ, Bruffaerts R, De GG, De GR, Gureje O. Use of mental health services for anxiety, mood, and substance disorders in 17 countries in the WHO world mental health surveys. LANCET. 2007;370(9590):841-50.

18. Khazanov GK, Cui L, Merikangas KR, Angst J. Treatment patterns of youth with bipolar disorder: results from the National Comorbidity Survey—Adolescent Supplement (NCS-A). J Abnorm Child Psychol. 2015;43(2):391-400.

19. Fleishman JA, Gebo KA, Reilly ED, Conviser R, Christopher MW, Todd KP, Hellinger J, Rutstein R, Keiser P, Rubin H. Hospital and outpatient health 
services utilization among HIV-infected adults in care 2000-2002. Med Care. 2005;43(9 Suppl):140.

20. Wang T, Zeng R. Addressing inequalities in China's health service. Lancet. 2015;386(10002):1441

21. Liu M, Zhang Q, Lu M, Kwon CS, Quan H. Rural and urban disparity in health services utilization in China. Med Care. 2007:45(8):767-74.

22. Li Y, Ma Y, Fang Y. The health service utilization of liver Cancer inpatients with different types of health Insurance in China. Value Health. 2016;19(3):A166-7.

23. Liang Y, Guo M. Utilization of health services and health-related quality of life research of rural-to-urban migrants in China: a cross-sectional analysis. Soc Indic Res. 2015;120(1):277-95.

24. Song X, Zou G, Chen W, Han S, Zou X, Ling L. Health service utilization of rural-to-urban migrants in Guangzhou, China: does employment status matter? Trop Med Int Health. 2016;22(1):82-91.

25. Lu L, Zeng J, Zeng Z. Demographic, socio-economic, and health factors associated with use of health services among internal migrants in China: an analysis of data from a nationwide cross-sectional survey. Lancet. 2016;388:S5.

26. Library WE: National Bureau of Statistics of China. 2005.

27. Dempster AP, Laird NM, Rubin DB. Maximum likelihood from incomplete data via the EM algorithm. J R Stat Soc. 1977:39(1):1-38.

28. Schafer JL, Graham JW. Missing data: our view of the state of the art. Psychol Methods. 2002;7(2):147-77.

29. Little RJA, Rubin DB. Statistical analysis with missing data. 2nd ed; 2002.

30. Peng Y, Chang W, Zhou H, Hu H, Liang W. Factors associated with healthseeking behavior among migrant workers in Beijing, China. BMC Health Serv Res. 2010;10(1):1-10.

31. Zou G, Zeng Z, Chen W, Ling L. Self-reported illnesses and service utilisation among migrants working in small-to medium sized enterprises in Guangdong, China. Public Health. 2015;129(7):970.

32. Mou J, Cheng JQ, Zhang D, Jiang HP, Lin LQ, Griffiths SM. Health care utilisation amongst Shenzhen migrant workers: does being insured make a difference? BMC Health Serv Res. 2009;9(1):214.

33. Guihua L. Demand and utilization of health Service for Floating Population in Xi'an. China Health Manag. 2012;29(2):154-7.

34. Hesketh T, Ye XJ, Li L, Wang HM. Health status and access to health Care of Migrant Workers in China. Public Health Rep. 2008;123(2):189-97.

35. Lu L, Zeng J, Zhi Z. What limits the utilization of health services among China labor force? Analysis of inequalities in demographic, socio-economic and health status. Int J Equity Health. 2017;16(1):30.

36. Janković J, Simić S, Marinković J. Inequalities that hurt: demographic, socioeconomic and health status inequalities in the utilization of health services in Serbia. Eur J Pub Health. 2010;20(4):389.

37. Chong Z, Feng T, Xingcai G. Prevalence and trend of two-week prevalence of urban and rural residents in China__— - based on longitudinal survey data from 1998 to 2013. China Health Stat. 2016;33(4):675-6.

38. Kexin L. Research on China's Household Registration System Reform. Marxist Acad J. 2017;5(1):204-14.

39. Lu L, Zou G, Zeng Z, Han L, Guo Y, Ling L. Health-related quality of life and its correlates among Chinese migrants in small- and medium-sized Enterprises in two Cities of Guangdong. PLoS One. 2014;9(1):e83315.

40. Ling LI, Chen QL. Evaluating three-year health care reform. Health Economics Res. 2012;53(3):89-105.

41. Jin $\mathrm{CL}$, Fen $\mathrm{LI}$. Conjecture of the health care reform in 2017. Chinese Health Resour. 2017

42. Arya N, Gibson C, Ponka D, Haq C, Hansel S, Dahlman B, Rouleau K. Family medicine around the world: overview by region: the Besrour papers: a series on the state of family medicine in the world. Can Fam Physician. 2017;63(6):436-41.

43. Zhang L, Liu S, Zhang G, Wu S. Internal migration and the health of the returned population: a nationally representative study of China. BMC Public Health. 2015;15(1):719-28.

Ready to submit your research? Choose BMC and benefit from:

- fast, convenient online submission

- thorough peer review by experienced researchers in your field

- rapid publication on acceptance

- support for research data, including large and complex data types

- gold Open Access which fosters wider collaboration and increased citations

- maximum visibility for your research: over $100 \mathrm{M}$ website views per year

At $\mathrm{BMC}$, research is always in progress.

Learn more biomedcentral.com/submissions 